\title{
The power of metonymy in humour: stretching contiguous relations across different layers of meaning
}

\author{
Sabina Tabacaru \\ Université de Lille 3 \& University of Leuven \\ sabina.tabacaru@univ-lille3.fr
}

\author{
Kurt Feyaerts \\ University of Leuven \\ kurt.feyaerts@arts.kuleuven.be
}

\begin{abstract}
This paper is grounded in Cognitive Linguistics $(C L)$, which sees metonymy as a conceptual phenomenon, in which one conceptual entity (the source) provides mental access to another entity (the target) within the same conceptual domain (Radden \& Kövecses 1999), as opposed to metaphor, which is seen as a mapping between different domains (Lakoff 1987). Our view on metonymy slightly deviates from the mainstream CL-approach, as we reinterpret the criterion of the single domain as an epiphenomenon of the conceptually defined contiguous relationship (Feyaerts 1999), which we take to be metonymy's categorical feature. In this contribution, we analyse the structural role of metonymy in humorous interactional sequences as they occur in the American television-series House M.D. and The Big Bang Theory. As our examples qualify as staged communicative acts, the interpretation of which involves processing meanings on different layers, we use Clark's (1996) layering model to account for the humorous uses of metonymies and to show that metonymic connections lie at the heart of pragmatic inferencing. In line with - and at the same time extending - earlier work (Feyaerts \& Brône 2005) on the potential of metonymic chaining to generate humorous and expressive meanings, this study demonstrates how a metonymic relationship may extend across different layers of meaning - the 'serious' discourse base space and a 'non-serious' pretence space - to generate a humorous meaning, based on the common ground between the speakers and the audience.
\end{abstract}

Keywords: humour; metonymy; layering; reference-point; inferencing. 


\section{Introduction}

The present paper focuses on the exploitation of metonymy for humorous purposes. More specifically, we will discuss examples in which the successful achievement of the humorous interpretation involves the activation of different layers of meaning (Clark 1996) as well as the exploitation of metonymic links, which constitute the essence of culturally determined social stereotypes (Feyaerts 1999). On the basis of a video-corpus, we empirically demonstrate that metonymy, which we define as a contiguity-based reference-point phenomenon, can be stretched across different layers of meaning, thus achieving a humorous effect. We base our observations on data drawn from a corpus of staged interactions in two contemporary American television-series. The data we gathered allowed us to focus on types of humorous utterances and construal operations involved in the production of humour.

The paper is structured as follows: in Section 2, we take a closer look at the layering model as explained by Clark (1996) that will be used later on for the analysis of humorous metonymies. In Section 3, we discuss metonymy as a contiguity-based reference-point construction, allowing a link to the inferencing model analysed in pragmatics. Then, in Section 4, we explain how we gathered and analysed the data. In Section 5, we present some examples chosen from the data set and relevant for our analysis, followed by the conclusions in Section 6.

\section{Humour in terms of layering}

Clark's (1996) model of layering can be applied to different types of situations, humour included (cf. Brône 2008; Tabacaru, 2014; Tabacaru and Lemmens, 2014). Figure 1 below shows the dynamics of the three-dimensional model proposed by Clark. According to Clark (1996: 16) "layers are like theatre stages built one on top of the other", hence Layer 1 and Layer 2 are constructions of the discourse spaces generated by an utterance or a certain situation: "Layer 1 is at ground level, representing the actual world, which is present in all forms of language use. Layer 2 is a temporary stage built on top of Layer 1 to represent a second domain" (1996: 16). It may be clear, then, that the primary or basic layer corresponds to the concrete situation of the communication between speaker(s) and hearer(s) (the 'ground' as Langacker calls it). On top of this primary layer, interlocutors may decide to create and elaborate another, secondary layer of meaning, which can only operate relative to and hence dependent on the primary layer of interpretation.

Clark notes that many conversations are usually structured in one layer, but, in the case of humour, the second layer is added. In other words, layering represents constructive discourse worlds based on "the surface level of the actual utterances" (Brône 2008: 2029). Just like other non-literal figures of speech, humour rests its success upon an apparent clash between what is said and what is intended (Sadock 1993: 42-43), a clash between Layer 1 and Layer 2 in this case. 


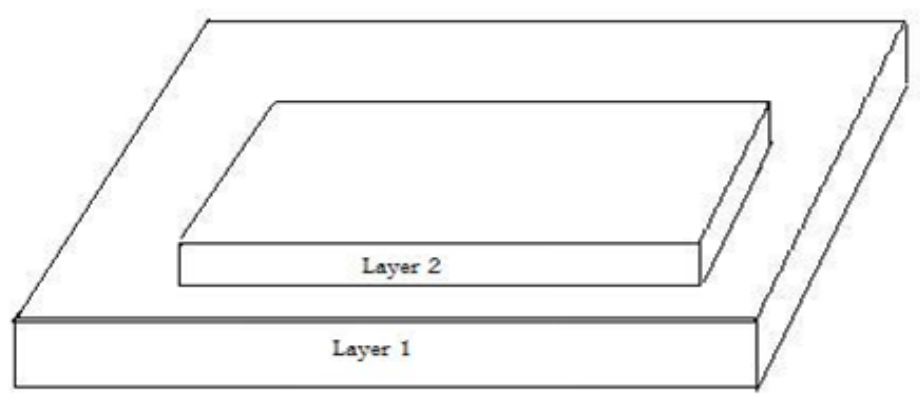

Figure 1: Clark's layering model

In order to visualize how layering unfolds and explains humorous utterances, Clark (1996: 353) suggests example (1), which is an exchange between a husband and wife regarding the husband's tutorial work. Ken mentions that he is not an expensive tutor, that he is cheap. Margaret's reply (I've always felt that about you) echoes Ken's statement that he is cheap, but adds a new meaning to the situation as a whole. Clark categorizes this as a tease, arguing that Margaret's reply does not represent a serious accusation, but rather a pretence. There is a serious/non-serious perspective ${ }^{1}$ that is to be taken into account, as non-serious assertions (i.e., the pretence) are created from the serious conversation:

$$
\begin{array}{ll}
\text { Ken: } & \text { and I'm cheap, - - } \\
\text { Margaret: } & \text { I've always felt that about you, } \\
\text { Ken: } & \text { oh, shut up, } \\
& \text { (- - - laughs) 15 bob a lesson at home }
\end{array}
$$

The connector is the adjective cheap, which allows adding a new meaning to the discussion. In Layer 1, Ken's interpretation of cheap is meant to be interpreted as 'inexpensive', whereas in Layer 2, the figurative meaning of 'vulgar' is added to the context. Clearly, Layer 2 is possible because of the common ground shared by the two speakers here. As a consequence, the non-seriousness of the added meaning is recognized as such by Ken.

\section{Metonymy as a contiguity-based reference-point construction}

Despite the interest Cognitive Linguistics has shown toward metonymy, there is still a lot of debate regarding its definition and its relation to metaphor. Generally, metonymy has been defined in comparison with metaphor, and the main focus has always been the latter. However, more recent studies have been concerned with the role of metonymy in cognition (Feyaerts 1999, 2003; Dirven 1999; Croft and Cruse 2004; Peirsman and Geeraerts 2006; Geeraerts and Peirsman 2011; Herrero Ruiz 2011, and others). As underlined by Peirsman and Geeraerts (2006: 269; see also Radden and Kövecses 1999), the central discussion in Cognitive Linguistics regarding metonymy basically revolved around its definition as a shift of meaning from one entity to another within the same domain (or domain matrix). In this view, the core distinction between metonymy and metaphor concerned the involvement of one or two conceptual domains (Lakoff 1987). Metonymy, then, provides a conceptual mapping between two entities belonging to the same conceptual domain, thus creating a substitution relationship (as in X STANDS FOR Y). As opposed to metaphor, metonymy serves the role of indirect reference, where one conceptual entity - the source — stands for 
another - the target (cf. Panther and Thornburg 2003). In the light of the difficulties to delineate domains or, for that sake, a domain matrix, this definition remains ambiguous and therefore rather problematic (Feyaerts 2003: 62-64).

In line with this observation, we subscribe to the view that metonymy can be defined in terms of a contiguity relationship between two linguistic or conceptual entities (i.e., source and target). Contiguity can be generally described as a close, non-similarity based association between concepts as can be observed among the elements of the same frame or between the frame as a whole and one or some of its elements (cf. Ullmann 1962; Feyaerts 1999) ${ }^{2}$. This view, crucially, does not contradict the often-cited criterion of just a single domain (matrix) being involved. The latter, however, is backgrounded as an epiphenomenon of the contiguity being established among two or more conceptual elements. When, in a usage event, two elements are represented as being causally related - regardless its plausibility let alone correctness in the 'real' world - both elements are construed as linked within a single conceptual frame. Adopted in a cognitive linguistic framework, contiguity is interpreted as conceptual contiguity, as argued by Dirven (1993: 14, and quoted from Feyaerts 1999: 64):

Contiguity cannot be based on any form of objective or natural contiguity. This has the farreaching implication that contiguity must be taken to mean conceptual contiguity and that we can have contiguity when we just "see" contiguity between domains. [our emphasis]

Especially with regard to the analysis of conceptual (metonymic) structures in humorous contexts, this conceptual predicate is of central importance as humour often hinges on the interpretation of unexpected, unreal(istic) or, for that matter, "incongruous" relationships between conceptual entities.

Within this contiguity-centered view, we side with Barnden (2010), who characterizes metonymy's cognitive function as a reference-point construction between elements ${ }^{3}$. The reference point phenomenon has been at the core of several cognitive processes, and aims at explaining how an element can be seen and referred to in terms of another. First discussed by Rosch (1975) in relation to prototypes, reference point constructions started from Wertheimer's (1938) claim that there are ideal types among perceptual stimuli that serve as anchoring points in perception (Tribushinina 2011: 216). The human brain will categorize these types as more salient than others, and will use them in order to categorize elements. Similarly, Langacker's $(1987,1999)$ view of reference-point constructions is a usage-based account, best described as the "ability to invoke the conception of one entity for purpose of establishing mental contact with another" (1999: 173, original emphasis). Figure 2 provides a schematic representation of the reference-point constellation, where $\mathrm{C}$ stands for the conceptualizer and $\mathrm{R}$ for the reference point used to trace a mental path to $\mathrm{T}$ - the target meaning. D represents the dominion, which can be best characterized as a set of potential targets, to which a reference point can gain access. The heavy-line circles describe salience. If one element can serve as a reference point for another, it does so mainly because of its salience. According to Giora $(1999,2003)$, salient meanings are accessed faster than less salient ones. ${ }^{4}$ In a given usage event, the element used as reference point must be salient for both the speaker and the hearer, in order for the utterance to be understood. 


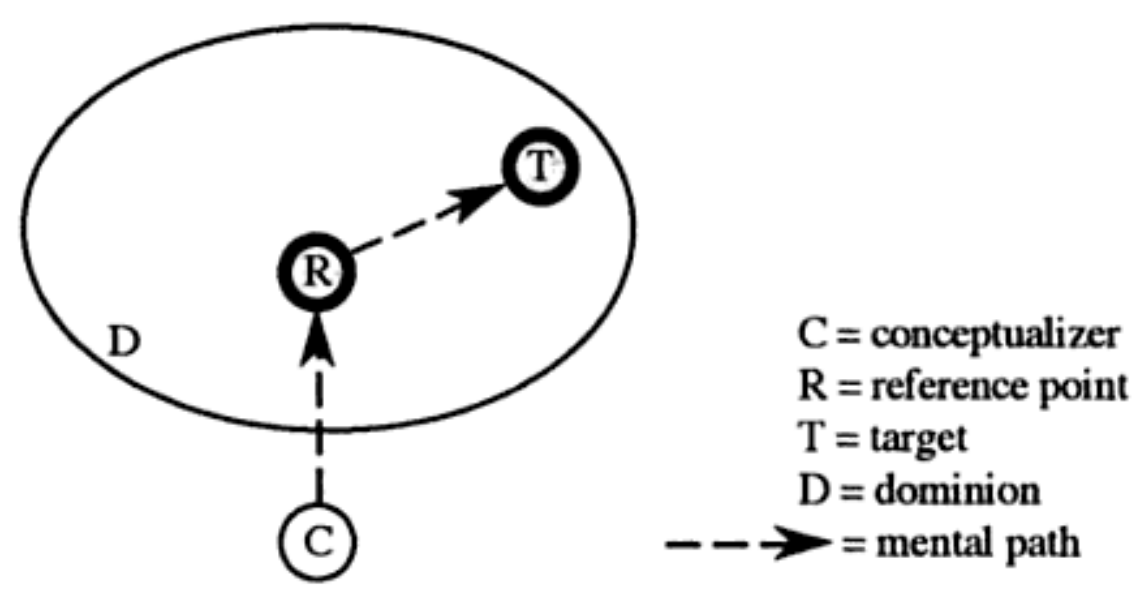

Figure 2. Reference point constructions (Langacker 1999: 174)

As pointed out above, metonymy has traditionally been discussed in relation to metaphor, but more recent analyses in Cognitive Linguistics have provided convincing empirical evidence that metonymy represents a fundamental cognitive process in its own right, on a par with metaphor (Feyaerts 1999, 2003; Koch 1999; Barcelona 2003). Moreover, Koch (1999: 139) notes that "metonymy occurs much more frequently than metaphor and tells a great deal about our cognitive equipment."

Following the view presented above, metonymy represents a "basic conceptual phenomenon" (Brône and Feyaerts 2003: 18) and is no longer considered a process of substituting a linguistic form by another. In non-humorous language use, it is almost always the most salient element of the conceptual frame that is being used in order to access another, less salient element in the frame or the entire frame. Speakers use the most salient element of a concept as a landmark for other elements that belong to the same cognitive model. Example (2) below is discussed in more detail in Brône and Feyaerts (2003: 19):

(2) A:

How did you get to the airport?

B: $\quad$ I waved down a taxi.

The verb "to wave down + [obj.]" prototypically refers to the entire scenario that constitutes B's arrival at the airport. A is able to infer that B waved a taxi driver, made him stop, got in the taxi, told the driver where he was heading, paid for the ride, got out of the taxi when they reached the airport. Nevertheless, from B's point of view, it is the "waving down the taxi" that constitutes the most salient element of this scenario, and from then onwards, A is going to follow the right track and infer metonymically - through a PART/WHOLE relationship - how B got to the airport. Similarly, a classic example such as (3) below follows the same train of thought, where interlocutors are able to infer metonymically to whom the speaker refers:

“The ham sandwich wants to pay." (Nunberg 1979)

As already pointed out by Brône and Feyaerts (2003), this sentence can be used by a waiter or waitress in a restaurant in order to refer to a client. The salient concept of FOOD (or, to be more specific, the HAM SANDWICH) is a reference to that particular customer, whose name is probably unknown and irrelevant to the restaurant staff. In the conceptual frame of RESTAURANT, this element is the most salient entity, which allows mental access to the conceptual element of the client. Langacker notes (1993: 30) that "a well-chosen metonymic expression lets us mention one entity that is salient and easily coded, and thereby evoke- 
essentially automatically - a target that is either of lesser interest or harder to name". As such, in example (3) above, and in the context in which it is uttered, the most salient entity is a reference for a less salient one, difficult to code.

Consider also Figure 3 below from Brône and Feyaerts (2003) used to describe examples (2) and (3) above ${ }^{5}$. The salient reference points refer either to an element belonging to the same frame, or to the frame as a whole:

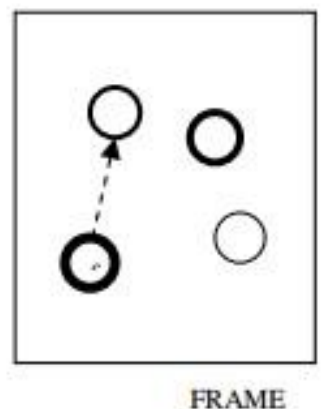

The ham sandwich wants to pay (salient reference point to an element in the same frame)

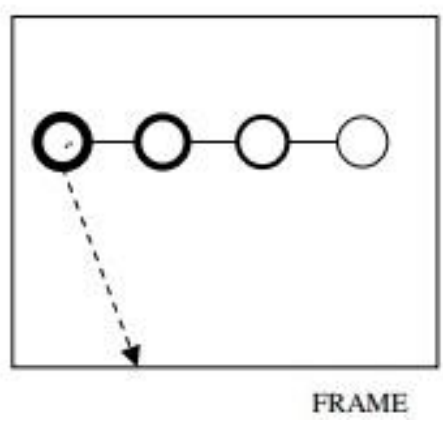

I waved down a taxi (salient reference point to the whole frame)

Figure 3. Brône and Feyaerts' (2003: 20) view of metonymy

It may be clear that this view on metonymy is not a license for an anything-goes devaluation of metonymy as the main restriction is the identification of a contiguous relationship holding between two verbal or conceptual entities. Also, a metonymic relationship requires a linguistic or conceptual element to be used in the functional context of a usage event. When spotting sails on the horizon at sea, one may refer to the entire ship by saying something like those five sails are approaching fast. Yet, when later discovering the same ship lying in the harbour, one cannot use the same metonymic expression anymore because in the usage event at hand, there is no functional relationship between the sails and the entire ship. Accordingly, we disagree with an anonymous reviewer of our contribution stating that "all words evoke meanings or rules or contexts or scripts, so in that very weak sense every word is metonymic". 6 The mere evocation of these associated meaning elements does not automatically qualify them as metonymic extensions of the primary use of the word or expression under concern. It should be noted as well that the meaning extensions identified in (2) and (3) do qualify in this context as PART-FOR-WHOLE metonymies. ${ }^{7}$

\section{Metonymy underlying patterns of humorous creativity}

In their study of the conceptual mechanisms underlying the rich variation patterns occurring in contexts of creative and expressive language use, Feyaerts and Brône (2005) provide a corpus-based description of the way in which a metonymic relationship can be stretched without losing coherence with the intended target. They illustrate their case with German insults for stupidity. In an attempt to avoid using routine-like, worn-out utterances in an expressive context, interlocutors creatively elaborate the metonymic source concept in a nonconventional way, thus achieving a surprising or, for that matter, humorous effect with every utterance. 
As opposed to metaphorical mappings, in which image-schematic and logical structures are projected from one domain onto another, metonymy allows the construction of conceptual chains, in which the target of a first metonymic extension also serves as the source for a second metonymy, and so on. This results in the processing of a metonymic chain in which the source concept presupposes the mental activation of several 'intermediate' steps in order to reach the intended target.

(Feyaerts \& Brône 2005: 20)

In line with the Optimal Innovation Hypothesis as described by Giora et al. (2004), this chaining potential of metonymy provides an excellent mechanism for the construction of stimuli that are innovative, expressive or even plainly humorous, but which at the same time link back to a (partly) conventionalized meaning. These metonymic chains may even stretch beyond the boundaries of a single domain, thus interacting with the metaphoric conceptualization of the intended target concept.

[I]n the process of creating novel, expressive utterances, metaphor unlike metonymy hardly serves the goal of constantly innovating the conceptual relationship between source and target concept without losing contact with the established, conventionalized imagery. (...) Importantly, however, the application of conventional metaphors allows metonymic reasoning to unfold in different domains, which are all related to the same target structure.

(Feyaerts \& Brône 2005: 11)

Feyaerts and Brône (2005) discuss, among others, examples like (4)-(6) in which stupidity is profiled through the schematic image of a damaged container, which in these cases is elaborated as the conventional metaphor of the HUMAN BODY AS A BUILDING. In (4) the deviance as such is made explicit, thus instantiating the basic metonymic mapping, according to which a bodily deviance stands for a mental one such as stupidity. Interestingly, the expressions in (5) and (6) reveal a pattern of metonymic creativity as the concept of the damaged building becomes metonymically construed in terms of some sort of violent action causing the damage.

\section{Her roof is damaged}

Bei dir haben sie wohl eingebrochen

You must have had a break-in, right?

\section{Ihm haben sie wohl eine Ecke abgefahren \\ Someone must have cut off one of his edges}

Feyaerts and Brône (2005) observe a comparable pattern of metonymic innovation in (7)-(9), in which another conventional metaphor (HUMAN BODY AS MACHINE) is instantiated. Whereas in (7) the cause of the defect is the reference point, (8) expresses a prominent effect of the defect. In (9), finally, the metonymic link leading from source to target concept is stretched even further as the former highlights some sort of behavioural manifestation of having a screw loose hence being stupid.

(7) Bei ihm ist eine Schraube locker

He has a screw loose

Ihr raucht der Kopf

Her head is smoking 
Du brauchst wohl einen Schraubenschlüssel?

You probably need a screwdriver?

As it turns out, in humour, salience is the factor being exploited in order to manipulate the interpretation process and thus puzzling the hearer (cf. Giora 1999, 2003; Brône and Feyaerts 2003; Feyaerts and Brône 2005). Unlike non-humorous examples like (2) and (3), in which metonymy serves the communicative and cognitive goal of maximizing the efficiency of the interpretation process, metonymy in humorous utterances hinges on non-salient and unexpected reference-points, through which the interpretation routine of the interlocutor is de-automatized and pleasantly misled. Yet, in the end the latter is still expected to successfully infer the metonymic steps leading to the intended target concept.

Unlike the examples and analysis presented in Feyaerts and Brône (2005), our present study concerns the identification of metonymic patterns in humorous interactional sequences in television series. Our analysis does not concern the interplay of metonymy with other conceptual structures such as metaphor, but rather its interaction with the different layers of meaning (Clark 1996) that are involved in these sequences. In the light of the findings presented in Feyaerts and Brône (2005), we expect metonymy to play an important role in this interactional type of humour as well. In the next section, we present the data and methodology that we used, followed in section 6 by a discussion of some relevant examples from our corpus.

\section{Data analysis}

Like others (Brône 2008; Uhlig 2009) before us, we chose to work on data already available to the public. The instances were collected from two contemporary American televisionseries: House M.D. (2004-2012) ${ }^{8}$ and The Big Bang Theory (2007-). We chose these two series because of their disparity: while the latter one is widely known as a sitcom, the former one is a drama, which does include, however, a great deal of humorous instances, often characterized by critics as part of sarcasm and witty remarks (which are by definition humorous). The corpus thus formed provides a wide range of examples and situations, from the daily life of successful but nerdy scholars to the medical environment and witty remarks of Dr. House. We believe our data to be balanced, mainly because it assumes different perspectives (and different writing techniques) on how humour is created. Consequently, we hope to shed some light on aspects that are still unknown to the linguistic research on humour so far.

The corpus consists of $9 \mathrm{~h} 38 \mathrm{~m}$ of video and more than 80,000 words that were annotated using ELAN $^{9}$, which allowed us to create complex annotations at different levels (called 'tiers' in ELAN). The project consisted of analysing humorous instances, depending on their type which were then classified according to the semantic mechanism involved. Firstly, concerning the first tier - humour types - we have used Feyaerts' (2013) typology ${ }^{10}$ that has been developed for the Corinth corpus ${ }^{11}$. This classification included 23 humor types, ranging from sarcasm and irony, to inter-textual, or even sexual humor. ${ }^{12}$ Secondly, for the linguistic mechanisms on which these humor types were based, we have used several classifications: Grice's (1975) implicature, Raskin's (1985) idea of script-opposition, Croft and Cruse's (2004) construal operations and Brône's (2008) typology of hyper- and misunderstanding. Our current topic, metonymy, represents just one such mechanism, alongside with, for instance, construal operations such as metaphor, figure-ground reversal, layering, etc.

The data provided us with no less than 173 metonymic instances $(20.1 \%$ of the total linguistic mechanisms used in the corpus) ${ }^{13}$ some of which will be discussed in more detail 
below. The selected examples below show how in humorous sequences cognitive frames need to be accessed through non-salient reference points, which de-automatizes the initially expected interpretation routine (see section 4 above). In producing humour, the speakers in the following sequences manipulate the interpretative procedures and cognitive abilities hearers are most likely to go through in order to puzzle them when looking for appropriate interpretations. Yet, in order to make sure the interlocutors reach the envisaged humorous interpretation, the reference points still need some transparency with regard to the target. Therefore, the elements that are highlighted, be they rather unexpected and surprising, still belong together in the same frame and give the hearer enough information to successfully process the humorous meaning through pragmatic inferencing. We show that metonymy is thus exploited through humorous creativity, as it manipulates the reference point structure by using less salient features of a cognitive model and thus directing the metonymic interpretation into a non-serious pretence layer (Clark 1996).

The examples discussed below were all categorized as humorous and are inherently metonymic. We show that humorous metonymies allow the hearer to retrieve the original frame from a PART-WHOLE perspective. Nonetheless, these patterns follow the same line of thought as examples (2) and (3) presented above, the only difference being that they manipulate salience in order to reverse the meaning of the utterances. Hearers have to be able to access a pretence space (or a second layer) that hinges on the common ground speakers share between them. In its prototypical use, metonymy offers the reference point that hints to the right path hearers have to follow in order to access the intended interpretation. However, as illustrated in section 4, in humorous sequences, hearers are being 'tricked' into accessing an inappropriate and surprising meaning forcing them to reinterpret the reference point in a non-salient way instead. The appropriateness is achieved by the humorous interpretation ("resolution"). Section 6 below presents a more detailed analysis of some of these examples.

\section{Metonymy in interactional humor}

Consider example (10) below, where two metonymic instances unfold one after the other. We discuss this example from a narrative perspective that presents House (the white boss) and Foreman (the African American employee). Dr. House's initial words are intended as a tease. Following Clark's layering model, this tease happens in a pretence space (i.e., non-serious discourse space, as presented in section 2 above), and not in a serious space. As such, it is expected not to be taken at face value. House's intended implication is that one of his employees (Foreman) knows everything about drugs since he is African American. Regarding the humor type, and following Feyaerts' (2013) typology, this example has been categorized as involving [stereotype humor], [sarcasm] and [tease], playing on the social and geographical stereotypes people generally make use of:

(10) House: [To Foreman] I want you to go to his house and find his stash. I bet you know all the good hiding spots.

Foreman: Actually, I never did drugs.

House: [To Cameron] Better go with him, in case he gets high.

The two utterances used by the speaker (House) represent sarcastic teasing toward his African American employee. The sarcastic teasing immediately introduces the pretence layer, which can be maintained successfully on the basis of the rich common ground shared by both Dr. House and his long-year employee, Dr. Foreman ${ }^{14}$. The implications are possible because of his employee's racial ethnicity of which everyone is aware. As a stereotype, in America, the black community is believed to be engaged in illegal activities, and is often associated 
with the use of drugs, as pointed out by Mauer (1999). ${ }^{15}$ That is why House, out of the three employees he has, chooses Foreman (the only black person on his team) to go search for drugs into a patient's house. The sentence I bet you know all the good hiding places implies that he must know where a person generally thinks of hiding their stash because he must have been involved with drugs at some point. When Foreman, visibly annoyed by House's remark, mentions that he never did any drugs, House names another person (Cameron) on the team to accompany him in case he gets high. Thus, the humorous implication is repeated, in the sense that, as a black person, Foreman is most likely to use these drugs when finding the patient's stash.

In terms of analysing this example as a metonymic expression, the target frame AFRICAN AMERICAN is accessed through some very stereotypical features, viz. 'all blacks are involved in criminal drug deal business'. The metonymy of referring to an entire person (or ethnic group) by singling out a specific feature (using or dealing drugs) immediately activates the stereotype in its most rigid, conventionalized and therefore also widespread form. In the context and situation of an intellectual surrounding, which consists of a team of highly educated people (doctors), it is the blunt and un-nuanced reference to this stereotypical feature with regard to a coloured colleague that provokes an incongruity in the communication process, indicating the need to include a pretence layer and thus triggering the humorous interpretation of teasing. The same goes for example (11) where the same frame is built in order to mock the same African American employee, using the stereotypes concerning his ethnicity. The AFRICAN AMERICAN frame will call to mind negative ideas, such as 'drugs' or 'jail':

(11) Foreman: You know, if we cure Matt, he can use his close brush with death on his college essays. Admission guys love that stuff.

House: That's how you got in, right? Jail house diary?

In order for humour to work, the highly educated speaker emphasises these negative stereotypical cliché features people associate with African Americans. Metonymy, then, is the reference point construction which conceptually links the serious space of a medical team having a professional conversation and the non-serious space of popular stereotypes. Clearly, the interlocutors in this context (in the series) as well as the audience know this is a nonserious claim, a humorous one. It is to be interpreted as highly inappropriate as it unexpectedly highlights some negative aspects of the stereotype, which count as contextually non-salient features of the frame. Moreover, we are able to make the connection between African Americans and the jail house diary as we know that this is only a pretence built on the shared background between the audience and the television-series. Just like waving down the taxi in (2) or the ham sandwich in (3), we follow a path of contiguous relationship(s) leading to the intended interpretation, but at the end of it, so to speak, we are surprised by the giant leap which needs to be taken in order to reach the target, very much like the examples with stretched metonymic chains as discussed by Feyaerts and Brône (2005; see section 4). Comparable to their complex conceptual structures involving an interplay between metaphor and metonymy, our current examples also reveal metonymic relationships scanning across major, rather stable conceptual structures. This time, however, these structures do not identify as knowledge domains triggering metaphoric mappings, but as meaning layers triggering socalled 'staged communicative acts' (Clark 1996: 368).

Consider example (12), categorized again as stereotype humour and sarcasm, but aimed at a different people, this time Canadians. As a fixed idea, it is generally believed that Canadians are very polite and nice people, the idea which allows the speaker here to create the same metonymic inference. In this example, House tries to annoy one of the patients 
(Jeff), by intentionally stomping his cane (Dr. House's) on his foot (Jeff's). Jeff's wife (Deb) gets irritated, but he does not, which makes House infer that he is Canadian:

(12) House: Sir, why do you have two lunches in front of you?

Jeff: $\quad$ Been here for two meals.

House: $\quad$ And you're happy with that?

Jeff: [Shrugs] I just don't see much use in complaining.

[House stomps his cane on Jeff's foot]

Deb: What the hell?

Jeff: $\quad$ (smiling) I'm sure it was just a mistake.

House: [to Cameron] Is he Canadian?

When the word Canadian is uttered, the hearer is able to retrieve the inference from their common knowledge and beliefs, understanding the intended meaning. 'Extremely nice' becomes the feature standing for the whole CANADIAN frame (although it is not the most salient feature). The fact that it is this exact feature that is being highlighted as opposed to others adds the new layer to the reading of this example. Just as in the previous examples, the humorous effect is achieved through the unsubtle recycling of a patient's behaviour (or, the lack thereof) as a metonymic reference point, which teasingly leads to the CANADIAN stereotype as the target concept. In this case, the unexpected introduction of this target concept forces interlocutors and audience into a humorous interpretation in which, again, sarcastic teasing and therefore also a second, pretence layer is involved, which successfully relies on the assumed common ground among all communicative parties involved. In more technical terms, only the introduction of the target concept in Dr. House's question Is he Canadian forces interlocutors and audience into a post hoc reinterpretation of the patient's non-aggressive behaviour as the required but unexpected reference point for motivating House's question as a humorous utterance.

In example (13), taken from the data gathered from The Big Bang Theory, the humorous meaning revolves around the same type of social stereotyping as before. Howard, the Jewish person in the series, wants his friend's approval to date his sister. His friend remains reluctant to the idea, to which Howard replies:

Howard: Is it 'cause I'm Jewish, 'cause I'd kill my rabbi with a pork chop to be with your sister?

The target here is represented by the Jews, this time a very well defined religious group (unlike in the previous examples). In his article about metonymic expressions of stupidity in German, Feyaerts (1999: 312) points out that social stereotypes can be described as cognitive models, which "reflect culturally established preferences and norm concepts which play a decisive role in people's judgment about typical properties of all kinds of personality types." In the cognitive model characterizing Jews, such elements as 'rabbi' or 'pork chop' are also present. Or, the butt of the joke here is precisely to highlight these features instead of others, to surprise the hearer and make them access the intended stereotype. In (13), apart from stereotype humour, the speaker also uses sarcasm, 'joint' fantasy, and self-deprecatory humour to create a metonymic pattern. More specifically, the expression "I'd" verbally marks a counterfactual space, in which the character describes - and exaggerates - the things he would do to date the wanted sister (to kill the rabbi with a pork chop). This description in the counterfactual space puts forward some of the main elements of (non-)Jewish culture (including the rabbi as the religious guide and the pork chop representing the sinful behaviour). It is as saying that by killing a rabbi with a pork chop, one no longer is Jewish, because the central elements of the frame JEWISH no longer exist. These elements are not 
salient as such for the cognitive model JEWISH (i.e., in layer 1), but, in the juxtaposition in this imaginary scene, they turn into contextually salient reference points, which structure this powerful counterfactual argument. On the basis of the cultural common ground about the Jewish culture, assumed to be shared by all interlocutors including the audience, the counterfactual in the pretence layer 2 can be easily accessed. Figure 4 below illustrates the understanding of example (13) from a layering perspective.

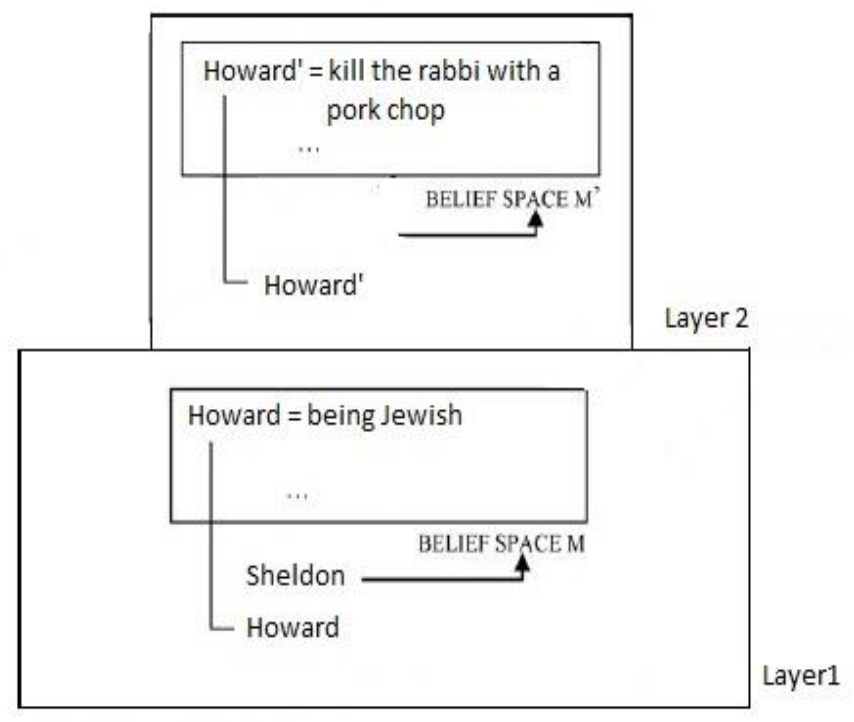

Figure 4. Layered meaning in example (13)

Compare it also with example (14) below, where 'typical behaviour' is brought into focus as well and is classified simply as stereotype humour. It can be explained by the PART FOR WHOLE relation or even that of CHARACTERISTIC FOR ENTITY (Feyaerts 1999; Peirsman and Geeraerts 2006). From this narrative perspective, Penny in (14) is pictured as playing a video game online, which includes certain quests. We can only see Penny in this scene; we cannot hear the other player, who is German. When she asks him to stay on her flank, we imply that he does not understand that word, to which she responds by yelling flankenzie, word that would imitate the sounds of the German language:

(14) [Penny playing a video game]

Penny: No, Fritz, I need you on my flank. No, I don't know German. Flankenzie! Flankenzie!

Similar to the previous examples, by means of metonymic inferencing on the basis of similarity with the English word 'flank', both interlocutors and audience are able to understand that the strange-sounding word flankenzie is to be interpreted as Penny's German sounding request to stay on her flank ${ }^{16}$. Because of its German sound, the strange word form flankenzie refers to the whole frame of GERMAN. The humorous metonymy in (14) comes from Penny's copying of the form and meaning of German words.

Consider also an example such as (15) below, taken from House M.D. and where the humorous scenario revolves around two metonymic structures. In this scene, Dr. House talks to a female patient to whom he announces she was pregnant:

(15) House: You were pregnant.

$[\ldots]$ 
Sarah: $\quad$ I haven't had sex since I split up with my husband. That was almost a year ago.

House: $\quad$ Fine, have it your way. Immaculate Conception.

Sarah: Um, what do I do?

House: Well, it's obvious. Start a religion.

House's sarcasm is obvious with the final advice to start a religion, as well as the suggestion that this could be Immaculate Conception. The sarcastic meaning is built through means of metonymy linking the source and the target. In this example, as stated above, we encounter two metonymies, both of which are included in the frame of RELIGION. Here, Dr. House, who clearly does not believe his patient (who claims she has not had sex for almost a year, and yet was pregnant), suggests Immaculate Conception as a valid excuse for her pregnancy. His advice to start a religion refers to Christianity and the birth of Jesus Christ.

If we look closely at this example, we can identify two metonymies at play in the humorous meaning of the message. The first one is represented by the phrase Immaculate Conception, which is the first reference-point to the religious meaning. This first metonymy helps build up the second one-start a religion - which introduces more explicitly the frame of RELIGION that was inferred from the first metonymy. Both metonymies refer to the same frame (i.e., RELIGION) which the hearer accesses automatically because the birth of Jesus Christ and the beginning of Christianity are part of the common knowledge that people share.

In contrast, the prototypical view of metonymy implies that salient elements are brought into focus in order for a hearer to access the intended interpretation (ham sandwich is salient in a restaurant where the customer is having a ham sandwich). However, example (15) is humorous because less salient, even absurd elements are brought into focus, especially in a serious environment (the situation presents a doctor with his patient, the topic revolves around an unknown pregnancy she had, etc.). The serious topic/scenario is incongruous with the sarcastic comment made by Dr. House, who mocks his patient by comparing her to the Virgin Mary.

The example below, also from House M.D., exploits the metonymical association CONDITION FOR PERSON. The humorous effect comes from trumping Stacy's intended meaning and mocking her utterance. In this scene, the speaker-Stacy-shows her anger towards House, who harasses her husband (Mark), now in a wheelchair. The metonymy is based on what the two of them have in common, i.e., a handicap: Mark is in a wheelchair after an accident, and House uses a cane:

(16) Stacy:

This is unbelievably difficult for Mark, which you should know, which you should be able to summon up some level of empathy for.

House: $\quad$ Right. The Crippled Boys. We should_start a band.

Sarcasm here includes both Mark and House, but also Stacy, and is built on what the two characters have in common, a problem with their legs. The metonymy can be transcribed as PART FOR WHOLE, or, more specifically, CONDITION FOR SUFFERER. Both Mark and House are seen in relation to their condition. The sarcastic utterance is built on the association made by Stacy in the first line, when she makes this connection between the two of them: which you should know, which you should be able to summon up some level of empathy for. The implied meaning is that House should be more sympathetic since he suffers from the same condition. House, however, takes this to a second level, a pretence space, where their common condition could make them start a band (The Crippled Boys). This is also created through constructional parallelism, as the names of most bands are construed with the definite article the and an adjective preceding a noun (e.g., The Dead Kennedys, The Rolling Stones, The 
Smashing Pumpkins, etc.). The suggestion that they should start a band is sarcastic, targeting not only Mark and House, but also Stacy, for making the comparison between the two of them.

Therefore, in the examples presented above, metonymy plays the role of linking the serious and non-serious spaces. It serves the role of a reference point construction able to link the many associations among elements.

\section{Concluding remarks}

In this article, we have looked at some examples of interactional humour sequences, in which metonymic structures are exploited in order to de-automatize the routine-like interpretation process and by doing so achieve a humorous effect (see also Brône and Feyaerts 2003). We have illustrated that the humorous exploitation of this contiguity-based reference-point phenomenon may involve the profiling of non-salient reference points or the unsubtle and contextually inappropriate explicitation of metonymic links that constitute popular social stereotypes. Undoubtedly, though, humorous effects can be achieved by more and different types of non-prototypical reference point reasoning than the ones described here.

In our examples, we have also demonstrated that these metonymic relationships trigger inference processes, which lead across the realm of what Clark (1996) labels different meaning layers. The successful interpretation of these metonymies appeals to the assumed common ground between audience and interlocutors and requires building a non-serious space on top of the communicative base space.

With regard to the role of metonymy in generating novel instances of humour, we observe an interesting structural analogy between the patterns described in Feyaerts and Brône (2005) and referred to in section 4 and the ones which we have identified in the present study. In both cases, the involvement of different conceptual domains or discourse layers offers some sort of scaffolding structure or two distinct playgrounds, across which metonymy may direct its contiguous mapping relations. From a conceptual point of view, metonymic reasoning appears to be an important driving force for generating humour as it can stretch and vary any contiguous relationship between the source and target concept or across different meaning layers.

In the light of the pervasiveness of metonymy as a conceptual phenomenon as well as the examples discussed in sections 4 and 6, it may seem that every humorous instance always involves some metonymic pattern. Although metonymy clearly qualifies as a pervasive and powerful conceptual mechanism, which is also very prominent in the generation and interpretation process of humorous utterances, it is not true that everything is metonymy. As already mentioned in section 3 , a metonymic mapping requires a contiguous relationship, the source concept of which serves as a reference point for attaining the intended target. This is not to say either that every case of reference point reasoning-humorous or not-hinges on metonymy. Other conceptual relationships such as metaphor and analogy also serve as strong and pervasive mechanisms in reference point constructions. A fine illustration to prove this point was provided to us by one of the anonymous reviewers, who referred to the sublime and strongly elaborated analogy between the narratives of Dr. House and Sherlock Holmes, the latter operating as some sort of analogical reference point for a full understanding of the popular television series. All the puns and subtle jokes, which are generated before this background, do not necessarily involve any metonymic pattern. Beside this example, there are plenty of other types of interactional humour (teasing, comical hypothetical, wordplay and punning, hyper-understanding, etc.), in which metonymy may play no role whatsoever. 
Finally, this study includes non-spontaneous interactions of humour, implying the work of writers, producers, actors in order to see a particular humorous message. Although it clearly has rendered interesting patterns involving metonymy, future research should include more spontaneous uses of the phenomenon.

\section{Notes}

${ }^{1}$ Raskin (1985) considered humor as a type of non-bona-fide communication which would violate the Gricean Cooperative Principle and maxims. These maxims were set as conditions for bona-fide (i.e., serious, sincere, usual) communication; by following the 'rules', one would ensure a successful exchange between interlocutors.

2 "Some of the most frequently cited illustrations of contiguous relationships include associative-functional relationships such as cause-effect, container-contained, producerproduct, part-whole, substance-object etc. In this diversity, metonymy differs from metaphor, in which the structural mapping between domains basically reduces to a relation of (conceptually embedded) similarity (A is like B)." (Feyaerts 1999: 64).

3 See also Norrick (1981: 27): "The line between principles of similarity and of contiguity is at times fuzzy".

${ }^{4}$ For instance, Giora's (1999, 2003) Graded Salience Hypothesis depends on some factors that make meanings behind words more salient than others: conventionality, frequency, familiarity, and prototypicality.

${ }^{5}$ It is clear that interlocutors access certain meanings (be they explicit or implicit) when they hear an utterance. In pragmatics, Relevance Theory (Sperber and Wilson 1988) refers to this process of comprehension, and underlines the role inferences play in this process. As such, the comprehension of a message depends on logical interpretations of utterances. When a speaker utters a message, there are logical entailments that hearers will construct as well as implicated premises and conclusions they reach given the context, in which they find themselves (cf. Zegarac and Clark 1999; Yus 2003).

${ }^{6}$ We thank two anonymous reviewers for commenting on an earlier version of this paper.

${ }^{7}$ There is an ambiguity in the dual concept of PART-WHOLE. It is important to distinguish (along with Seto 1999) between (a) a metonymic PART-WHOLE relationship as between BODY and ARM and (b) a non-metonymic relationship of synecdoche as between FUR and TREE. The former is a partonymic part-of relation between constitutive elements of a whole whereas the latter qualifies as a taxonymic kind-of relation between a subset and the overarching category (cf. hyponym vs. hyperonym in lexical semantics).

${ }^{8}$ See also Dynel (2014).

${ }^{9}$ ELAN is a tool for video annotation freely available for researchers from the Max Planck Institute for Psycholinguistics, The Language Archive, Nijmegen, The Netherlands (http://tla.mpi.nl/tools/tla-tools/elan/); see Sloetjes \& Wittenburg (2008).

${ }^{10}$ This typology is used for the CORINTH corpus, an open corpus of Dutch humour, which was gathered and analysed at the University of Leuven. It includes all the humour types discussed and defined in the literature so far.

11 See Feyaerts, Oben \& Brône (2007). Corpus Interactional Humor, University of Leuven.

${ }^{12}$ For more on this classification, see Feyaerts 2013 or Feyaerts et al. 2007.

${ }^{13}$ In our corpus, metonymy was the most frequently used linguistic mechanism. Other linguistic mechanisms were also identified: metaphor (11.4\%), figure-ground reversal $(10.6 \%)$, repetition $(6.8 \%)$, etc.

${ }^{14}$ Of course, the audience shares this common ground as well. 
${ }^{15}$ Mauer (1999) notes that "offenses by blacks are more likely to lead to arrest than those of whites" (p. 6) and that "Hispanic and African American inmates are more likely that nonHispanic whites to be incarcerated for a drug offense" (p. 9). The data show that in 1995-96, " $86 \%$ of people charged with crack trafficking offenses in the federal system were African American" (p. 9).

16 As a matter of fact, flankenzie is a phonetic representation of a correct German imperative (to be written as 'flanken Sie!'), ordering someone to cover one's flank.

\section{References}

Barcelona, A. (2003). 'The case for a metonymic basis of pragmatic inferencing: Evidence from jokes and funny anecdotes', in Panther K.-U. \& Thornburg L.L. (eds.), Metonymy and Pragmatic Inferencing, Zurich: John Benjamins, pp. 81-98.

Barnden, J.A. (2010). 'Metaphor and metonymy: making their connections more slippery'. Cognitive Linguistics 21 (1), pp. 1-34.

Brône, G. \& Feyaerts K. (2003). 'The cognitive linguistics of incongruity resolution: Marked reference-point structures in humor'. University of Leuven, Department of Linguistics preprint no. 205.

Brône, G. \& Feyaerts K. (2004). 'Assessing the SSTH and GTVH: a view from cognitive linguistics'. Humor: The International Journal of Humor Research, 17 (4), pp. 361-372.

Brône, G. (2008). 'Hyper and misunderstanding in interactional humor'. Journal of Pragmatics, 40 (12), pp. 2027-2061.

Clark, H. H. (1996). Using Language. Cambridge: Cambridge University Press.

Croft, W. and Cruse D.A. (2004). Cognitive Linguistics. Cambridge: Cambridge University Press.

Dirven, R. (1993). 'Metonymy and metaphor: Different mental strategies of conceptualization.' Leuvense Bijdragen 82 (1), pp. 1-28.

Dirven, R. (1999). 'Conversion as a conceptual metonymy of event schemata', in Panther K.U. \& Radden G. (eds.), Metonymy in Language and Thought, Amsterdam/Philadelphia: John Benjamins, pp. 275-288.

Dynel, M. (2014). 'Isn't it ironic? Defining the scope of humorous irony'. Humor: International Journal of Humor Research 27 (4), pp. 619-639.

Feyaerts, K. (1999). 'Metonymic hierarchies: The conceptualization of stupidity in German idiomatic expressions', in Panther K-U. \& Radden G. (eds.), Metonymy in Language and Thought, Amsterdam/Philadelphia: John Benjamins, pp. 309-332.

Feyaerts, K. (2003). 'Refining the inheritance hypothesis: interaction between metaphoric and metonymic hierarchies', in Barcelona, A (ed.), Metaphor and Metonymy at the Crossroads: A Cognitive Perspective, Berlin/New York: Mouton de Gruyter, pp. 59-78.

Feyaerts, K. (2013). 'Tackling the complexity of spontaneous humorous interaction. An integrated-classroom modeled corpus approach', in Gurillo L.R. \& Alvarado Ortega M. B., Irony and Humor. From Pragmatics to Discourse, Amsterdam/Philadelphia: John Benjamins, pp. 243-268.

Feyaerts, K. \& Brône, G. (2005). 'Expressivity and metonymic inferencing: Stylistic variation in non-literary language use. Style 39 (1), pp. 12-35.

Feyaerts, K, Speelman D., Brône G. \& Oben B. (2007). Corinth: Corpus Interactionele Humor. University of Leuven.

Geeraerts, D. \& Peirsman Y. (2011). 'Zones, facets, and prototype-based metonymy', in Benczes R., Barcelona A. \& Ruiz de Mendoza Ibáñez F.J. (eds.), Defining Metonymy in 
Cognitive Linguistics. Towards a Consensus View, Amsterdam/Philadelphia: John Benjamins, pp. 89-124.

Giora, R. (1999). 'On the priority of salient meanings: Studies of literal and figurative language'. Journal of Pragmatics 31, pp. 919-929.

Giora, R. (2003). On our Mind: Salience, Context and Figurative Language. New York: Oxford University Press.

Giora, R., Fein, O., Kronrod, A., Elnatan, I., Shuval, N. \& Zur, A. (2004). Weapons of mass distraction: Optimal innovation and pleasure ratings. Metaphor and Symbol 19 (2), pp. 115-141.

Grice, H. P. (1975). 'Logic and conversation', in P. Cole \& J.L. Morgan (eds.), Speech Acts [Syntax and Semantics 3], New York: Academic Press, pp.41-58.

Herrero R. J. (2011). 'The role of metonymy in complex tropes: Cognitive operations and pragmatic implications', in Benczes R., Barcelona A. \& Ruiz de Mendoza Ibáñez F.J. (eds.), Defining Metonymy in Cognitive Linguistics. Towards a Consensus View, Amsterdam/Philadelphia: John Benjamins, pp. 167-194.

Koch, P. (1999). 'Frame and contiguity. On the cognitive bases of metonymy and certain types of word formation', in Panther K.-U. \& Radden G. (eds.), Metonymy in Language and Thought, Amsterdam/Philadelphia: John Benjamins, pp. 139-167.

Lakoff, G. (1987). Women, Fire, and Dangerous Things: What Categories Reveal About the Mind. Chicago and London: The University of Chicago Press.

Langacker, R.W. (1987). Foundations of Cognitive Grammar, Vol. I: Theoretical Prerequisites. Stanford/California: Stanford University Press.

Langacker, R.W. (1993). 'Reference-point constructions'. Cognitive Linguistics 4 (1), pp. 138.

Langacker, R.W. (1999). Grammar and Conceptualization. Berlin and New York: Mouton de Gruyter.

Mauer, M. (1999). 'The crisis of the young African American male and the criminal justice system'. The Sentencing Project (Retrieved December, 2014 from www.sentencingproject.org).

Norrick, N.R. (1981). Semiotic Principles in Semantic Theory. Amsterdam: John Benjamins.

Nunberg, G.D. (1979) The non-uniqueness of semantic solutions: polysemy. Linguistics and Philosophy 3 (1), pp. 143-184.

Panther, K-U \& Thornburg L.L (2003). 'Introduction: On the nature of conceptual metonymy', in Panther K.-U. \& Radden G. (eds.), Metonymy in Language and Thought, Amsterdam and Philadelphia: John Benjamins Publishing Company, pp. 1-18.

Peirsman, Y. \& Geeraerts D. (2006). 'Metonymy as a prototypical concept'. Cognitive Linguistics 17 (3), pp. 269-316.

Radden, G. \& Kövecses, Z. (1999). 'Towards a theory of metonymy', in Panther K.-U. \& Radden G. (eds.), Metonymy in Language and Thought, Amsterdam and Philadelphia: John Benjamins Publishing Company, pp. 17-59.

Raskin, V. (1985). Semantic Mechanisms of Humor. Dordrecht: Reidel.

Rosch, E. (1975). 'Cognitive reference points'. Cognitive Psychology 7 (4), pp. 532-547.

Sadock, J.M. (1993). 'Figurative speech and linguistics', in Ortony A. (ed.), Metaphor and Thought, $2^{\text {nd }}$ ed., Cambridge \& New York: Cambridge University Press, pp. 42-57.

Seto, K. (1999). 'Distinguishing metonymy from synecdoche', in Panther K.-U., and Radden, G. (eds.), Metonymy in Language and Thought, Amsterdam \& Philadelphia: John Benjamins Publishing Company, pp. 91-120.

Sloetjes, H. \& Wittenburg P. (2008). 'Annotation by category - ELAN and ISO DCR'. In Proceedings of the $6^{\text {th }}$ International Conference on Language Resources and Evaluation (LREC 2008). 
Sperber, D. and Wilson D. (1988). Relevance: Communication and Cognition. Harvard University Press, Cambridge, Massachusetts.

Tabacaru, S. (2014). 'L'humour: une approche cognitive'. Revue Mosaïque 11, pp. 170-182.

Tabacaru, S. \& Lemmens, M. (2014). 'Raised eyebrows as gestural triggers in humor: The case of sarcasm and hyper-understanding'. European Journal of Humour Research 2 (2), pp. 11-31.

Tribushinina, E. (2011). 'Conceptual motivation in adjectival semantics: Cognitive reference points revised', in Panther K-U. \& Radden G. (eds.), Motivation in Grammar and the Lexicon. Amsterdam and Philadelphia: John Benjamins, pp. 215-231.

Uhlig, C. (2009). Humor in the TV series 'Gilmore Girls'. Germany: GRIN.

Ullmann, S. (1962). Semantics. An Introduction to the Science of Meaning. Oxford: Basil Blackwell.

Wertheimer, M. (1938). 'Numbers and numerical concepts in primitive peoples', in Ellis W.D. (ed.), A Source Book of Gestalt Psychology, New York: Hartcourt, pp. 265-273.

Yus, F. (2003). 'Humor and the search for relevance'. Journal of Pragmatics, 35 (9), pp. 1295-1331.

Zegarac V. \& Clark B. (1999). 'Phatic interpretations and phatic communication'. Journal of Pragmatics 35 (2), pp. 321-346. 